\title{
Improvement of the Quality of Education as a Factor of the Improvement of the Effectiveness of Innovation Processes Management in the Economy
}

\author{
Olga Gennadievna Nazarova \\ Marina Alekseevna Muravyova \\ Valentina Valentinovna Silaeva \\ Tatiana Gennadievna Rebrina \\ Aleksandr Ivanovich Grischenkov
}

Bryansk State University named after Academician I.G. Petrovsky

Doi:10.5901/mjss.2015.v6n5s3p283

\section{Abstract}

\begin{abstract}
This article is dedicated to the search of the innovative ways to improve the educational system required for the formation of economic competence. The content and the structure of the concept of "economic competence" as a base, integral characteristic of the personal qualities of man, which reflects economic competence, provides an efficient and effective implementation of work in different areas of the economy according to socially accepted legal and moral norms, suggests the presence of managerial abilities, skills in analysis and work results forecasting, the concept of the effective and efficient opportunities for its implementation, professional mobility is specified. Expert economic competence is expressed in the unity of the personal, activity, cognitive spheres of subjects managing in the field of economy. The paper describes the technology of economic competence forming, based on such principles as focus on innovation; the development of systematic thinking, which makes it possible to take decisions at a high level of generality; informatization and also the principles of inter-disciplinary approach and the principles of humanization. The conceptually significant organizational and pedagogical conditions of educational process in the context of the formation of economic competence, an inextricable connection of the economy with all spheres of human activity, methods and techniques to restore the disturbed economic equilibrium in society training, the correction of the economic outlook are identified and justified. The means of economic competence formation are designed. The principal indices, criteria and levels of formation of economic competence of the individual are defined.
\end{abstract}

Keywords: innovation, education, the economy, the economic competence.

\section{Introduction}

A characteristic feature of the current world economic development is the transition of developed countries to a new stage of formation of an innovative type of society, i.e. the formation of an economy that is based primarily on the generation and distribution, the use of knowledge. The ability to adapt the unique abilities and skills to the changing reality, high qualification is the main factor ensuring the material prosperity and social status of the organization and the individual, leading manufacturing resource, a necessary condition to improve the efficiency of innovation processes in the economy of the state.

The most efficient way to invest resources is the investment in intellectual capital. The sharp decline in innovation cycles, the acceleration of the dynamics of renovation of products and technologies has been predetermined by the intensification of production, the use of new results of scientific and technical nature.

In accordance with the above, the students preparation to productive and valuable professional work in a modern market economy is one of the urgent tasks in professional training.

The stated requirements mean the following:

- the formation of the ability to react quickly to changing market relations;

- mobility;

- the formation of economic consciousness, which is characterized by a integral view on the system of economic relations;

- $\quad$ the formation of the economic competence of the individual, i.e. the ability to use economic terminology; 
- the comprehension of the mechanism of social and economic institutions functioning.

Modern production requires economically literate, competitive and professionally trained specialists. It presupposes a change in the entire educational system, its new content, the determination of the optimal conditions in the field of economic education, the use of new efficient advanced methods, techniques, means of educational activities.

The current system of students training is based on state educational standard of vocational education, on basic curriculum, on new, integrated list of professions. The introduction of subjects that are aimed at the study of modern processes taking place in the economy, at specialists training who can meet the needs of the market is taking place.

However, it should be stated that the qualitative component of the training of students is lagging behind the requirements of the labor market, employers. In line with this, the formation of the economic competence of the individual is one of the main trends in modern education.

\section{Literature Review}

Domestic pedagogues and psychologists have long been occupied with the problem of formation of economic competence. Its theoretical researches are carried out at different research areas.

\subsection{Subheading 1}

Some scientists (Evseenko \& Evseenko, 2002) indicate that the need for the formation of the economic competence of the expert is dictated also by a qualitative change in the situation of the subject of economic activities as a result of the establishment of market mechanisms in the regulation of social life and production.

\subsection{Subheading 2}

J. Raven believes that competence is a "specific ability required for the effective implementation of a specific action in a specific field and includes highly specialized knowledge, a special kind of substantive skills, ways of thinking and sense of responsibility for own actions" J. Raven (2001).

\subsection{Subheading 3}

In the report of W. Hutmacher, 1997 it is stated that there are different approaches to what is determined as a core competence. There may be two - be able to write and think, or seven: the learning; research; thinking; communication; cooperation, interaction; be able to work, to bring matters completely; to adapt to oneself, to accept oneself.

At a given stage in the modern science of economic competence is seen as the factor of a correct, rational economic behavior.

However, till now the complex research of the issues on formation of economic competence in the educational system has not been conducted. The technology for the formation of economic competence until now has not been the subject of special research. Besides, the importance of modern information technologies, which are considered to be a powerful factor for economic competence formation has not been studied thoroughly. Conditions, methods, tools, forms, criteria for the formation of economic competence are not identified.

\section{Objectives, Methodology and Research Design}

The objective of the study is:

- to theoretically prove and verify by the experiment the methods, forms, tools, conditions for the formation of economic competence.

The methodological basis for the study is both theoretical and empirical methods, including theoretical analysis, synthesis, analogy, scientific generalization, testing, observation, interview, questionnaire, evaluation of the students activity results, experiment, self-evaluation, methods of mathematical statistics.

The stages of the study. The study includes the following stages:

- the first stage - a searching preliminary study involving the theoretical analysis of the historical, philosophical, sociological, psychological, economic, educational and methodological literature on the problem of research. The objectives, problems, objects, object of research are determined; the general directions of the experimental work are presented. 
- the second stage - a pilot study involving determination of the content, methods and forms that provide the efficiency of economic competence formation; the identification of the key reasons for the development of the foundations of economic competence; the definition of indicators, criteria, levels of development of economic competence.

\section{Discussion of the Research Outcomes}

The increasing importance of economic literacy, taking active part in social processes, large amounts of economic information, personal and psychological characteristic of a modern market economy, and other represent clear indications of the specific features of the formation of economic competence.

The differences in the models of economic entities with respect to the administrative-planned approach to the enterprise and production management, social activity, the market economy also become significant.

These circumstances help to release the socio-economic factors relating to the establishment of the economic competence of future professionals which are in:

- the possibilities of abrupt changes in the characteristics relating to certain economic spheres;

- the managing of the economy on the basis of information and communication technologies, which provide the modeling as well as the prediction of alternative ways for its development;

- $\quad$ the specific problems of socio-economic nature solving through proper organization of economic activities and its efficient and effective management;

- the exchange of personnel between certain sectors of economic entities to enhance their qualifications and vocational preparation;

- $\quad$ the reform of the economic sphere;

- the development of new mechanisms for the economy functioning, etc.

The progress in the formation of economic competence today is due to the continuity of the forms and methods of work; to the appearance of innovation changes in the life of the people through socio-economic changes of social order; to the finding of economic foundation of democratic mechanisms; to the recognition of the freedom of producers in the market; to the creative activity of a chore.

According to our opinion, the essence of economic competence becomes apparent in the fact that it can occur only in the organic unity of the economic value of a person; in other words, in the context of a strong personal interest in the economic activity, the presence of internal motivation of an individual to conduct a qualitative and economic work, the attitude towards this work as a value is expected.

It should be noted that competence is a manifestation of competencies that are its component structure.

There is no doubt that the concept of competence includes theoretical knowledge in the academic field, prompt practical use of this knowledge to specific situations and leads to an adequate expression of human social life.

In the field of professional economic competence one can distinguish such competences as:

- the ability to analyze, synthesize economic information;

- $\quad$ the ability to use economic knowledge in practice;

- the ability to adapt to new economic situations;

- $\quad$ system competence, i.e. a systematic understanding of knowledge transfer;

- Innovation abilities;

- moderation, i.e. the ability to manage groups - partners, colleagues - without the use of methods of administrative and managerial character; capacity for integration interaction, different opinions and approaches prompting; the ability to stimulate creative economic behavior (The Glossary of Terms of the Labor Market, 1997).

The above competencies are made up according to the study of Western European employers (TUNING).

The general culture of people is expressed in their civic and humanistic orientation, broad outlook, spiritual interests, social activity, and the system of scientific knowledge, which form the world outlook.

With regards to our case, the economic outlook is a determinant step for the formation of economic culture, for which economic competence and its competence act as a structural unit I.A. Zimnyaya (2004).

The formation of economic competence, which is a structural unit of economic culture, at present is not disputed; but the process of its development require clarification both the content and the structure of the concept itself.

According to our opinion, before talking about the concept of economic competence, one should define the notion of competence.

Today, economic competence is often considered as a combination of economic knowledge and skills that are 
essential resources of both personal and social development, activity process for a more complete mastery of economic competence (Kuz'minov, 1993 \& Formation of Economic Competence of senior pupils, borytko.nm.ru/papers/subject 5_l/fadeeva.htm).

On the basis of the carried out analysis one should clarify the definition of economic competence.

Economic competence is a basic, integral characteristic of human personality traits, which reflects economic jurisdictions, provides an efficient and effective implementation of work in different areas of the economy according to socially accepted legal and moral norms, suggests the presence of managerial abilities, skills in analyzing and forecasting the results of activities, in the presentation an effective and efficient opportunities for its realization, professional mobility. Expert economic competence is expressed in the unity of personality, activity, cognitive spheres of economic actors in the field of the economy.

We examined the factors of economic competence formation in areas such as:

- the cognitive-empirical layer of economic competence, which reflects both theoretical and practical experience of economic work;

- the socio-cultural aspect of economic competence, which includes the basics of social and economic values, accumulated by previous generations;

- the professional level of economic competence that defines the development of the individual professional activity structures of a person on the basis of accounting requirements, which are determined by the level of the development of social order;

- the personal and psychological layer of economic competence, which involves the development of the valuemotivational orientation of economic activity;

- the historical and geographical layer of economic competence, which reflects the specifics of economic culture formation, depending on the climatic and geographical conditions, the characteristics of the mentality, ruling regime, etc.

- Undoubtedly, the need to consider economic competence as a complex system is dictated by the structure of economic activity. Full creative activity put in economic activity envisages the increase of the level of economic culture of the individual and, consequently, its economic competence. One should emphasize such levels of creative potential of the person in the process of economic work as productive-reproductive creativity, generative creativity, constructive innovation activity (Formation of Economic Competence of senior pupils, //borytko.nm.ru/papers/subject 5_/fadeeva.htm \& Uvarova, L.I., 2001).

The base of economic competence, according to our opinion, should be considered comprehensively, i.e. in the aggregate of its components - world outlook, consciousness, literacy, thinking and behavior O.G. Nazarova (2008).

Economic literacy serves as a certain level of education of individuals, which is characterized by the presence of combined economic knowledge, abilities and skills in economic categories operating, in understanding of the major economic laws, of the complex view of rational methods of work with the resources available, the mastery of basic techniques and methods of effective economic activity management O.G. Nazarova (2008).

Economic consciousness is regarded as the ideological source of creative work in the field of economics, valuable and normative foundations of economic life. The problem of economic education is to help to grasp the importance of social values in the sphere of economy, of the understanding of the meaning of the rules, as well as their personal and social values.

The main characteristic of the economic consciousness is economic thinking, which manifests itself in the logical culmination of the understanding of economic activity, its processes and patterns, in the mental ability of the individual to the economic transformation of different economic sectors O.G. Nazarova (2008).

Economic thinking ensures the integrity of both theoretical and activity components.

The theoretical aspect of economic thinking is characterizing:

- $\quad$ the complexity of the perception of economic entity by a professional;

- $\quad$ the conceptual-shaped nature of the human mind;

- the characteristics of the economic processes in the human mind.

The practical aspect of economic thinking reflects:

- the ability to understand the development trend of the economic process;

- the existence of the thinking skills of analysis, synthesis, comparison and generalization;

- a free use of economic categories and economic images;

- $\quad$ the ability to move quickly from concept-shaped economic ideas to action and back again.

Economic thinking is an understanding of the complex of the integral economically changed views on the activities of the company, characterized by a complex economic picture of the world, by the knowledge of the content of the 
processes that occur in the global economy, by the reasonable understanding of the basic characteristics and patterns of development, by the system of values that govern economic activities of people, providing the optimal amount of resources consumed O.G. Nazarova (2008).

Economic behavior is the individual implementation of any form of activity that has an impact on the economic situation, economic development, and serves as a kind of channel of human impact on the economy O.G. Nazarova (2008).

The teaching of the technology of restoring the disturbed economic equilibrium in society; the absolute guarantee of this technology assimilation, the focus of the educational process on the formation of world view, i.e. on the inextricable connection of the economy with all spheres of human life; the correction of economic knowledge, skills, abilities, thinking and understanding of the world, the transformation of consciousness, i.e. the personality; the transmission of the necessary information about the economic regularities are necessary preconditions for economic competence formation (Muraveva M.A., Nazarova O.G. \& Silaeva V.V., 2014).

The technology of the formation of economic competence is based on principles such as the focus on innovation, focused on the creative activity of students; the development of systematic thinking, which makes it possible to take decisions at a high level of generality; informatization of education provided by the inclusion of the educational system in the global information field, as well as the principles of liberalization and inter-disciplinary approach.

In our understanding, the formation of economic competence can be represented as a multi-level, complex system, which includes components such as a procedural-activity, cognitive, valuable and informational-communicational.

The procedural-activity component determines both practical and practice-oriented elements of economic competence, as well as the activity-procedural side of the subject of the economy. This element is based on a system of practical and practice-oriented skills that are the foundation of economic activity.

The cognitive component of economic competence determines, in particular, the intellectual development and characteristics of the cognitive activity of the individual engaged in the sphere of economic activity.

The valuable component of economic competence determines the level of economic and cultural development of the individual.

The informational-communicational component of economic competence gives the characteristic tactics and strategies of economic behavior of economic agents, channels of communication, the specificity of interaction, interpersonal relationships, communication, appearing in the course of economic activity E.I. Evseenko \& F.P. Evseenko (2002).

In order to determine the direction of economic competence development, we analyzed the interconnection of the blocks of economic education content, their constituent disciplines and teaching methods with the formation of a particular element of economic competence.

Further development and improvement of the educational process requires the following conditions:

- $\quad$ the formation of students economic competence through a substantial angle of view;

- the orientation of the education process for the development of economic consciousness, thinking and outlook. This will create favorable conditions for the formation of students' attitudes to economic competence, deliberate nature of its formation, as an element of the general culture of the person;

- the use of information methods. These methods contribute to the creation of a data bank of an economic nature, on the basis of which the cognition of the objects and subjects of the economy is taking place;

- the revival of independent work, focused on the search and analysis of economic information;

- $\quad$ the setting for the development of economic activities in the practical skills of future professionals;

- the active nature of learning, contributing to the development of the practical orientation in the development of economic skills.

To implement these directions, in the first place, it is necessary that each block of the content of economic education (special, general professional, educational, professional, practical training) and their constituent subjects fully contribute to the formation of specific structural components of economic competence.

It is important to understand that each of these blocks involves the development of various elements of economic competence and the formation of a model of economic competence.

For example, blocks of general education and general professional training contribute to the development of the most important business skills relevant to a variety of professional fields and lay the foundation for economic competence of such elements as economic knowledge, skills, economic thinking and consciousness.

Blocks of professional and special disciplines create the necessary conditions for the development of consciousness and economic thinking for the future. Workshop on economic subjects enables students to visually compare the knowledge gained with the possibility of its use in practice, creating a comprehensive knowledge about the 
peculiarities of economic activity. The totality of the mastered economic knowledge, experience and practical work contributes to the development of figurative and emotional relationship to economic activity, thereby creating the preconditions for the formation of the economic outlook.

Inservice training (specifically - industrial practice), being one of the main components of professional training allows a student to get an idea of the various forms and methods of economic activity, to determine the most efficient model for its implementation.

In most cases, in practice, an essential element of economic competence - economic behavior is formed. This is explained by the fact that only in the course of professional activity students face with a shortage of many material resources, see the actual reality, face with the need to perform a role of a social nature. This usually leads to the need to develop a strategy for appropriate behavior in a collective by establishing formal and informal interpersonal relations. Under these conditions, business communication skills are updated and secured; the experience of establishing communications with colleagues and customers is acquired.

As one can see, the process of students' economic competence formation involves the model development that includes in its membership the economic competence and presents the required professional and personal qualities of the student. This model is an integrated, interrelated process. In this process, all its components are aimed at achieving a common goal - the formation of economic competence.

Undoubtedly, at the moment the problem of computerization of the educational process, which has become urgent because of the wide spread of information technology in a variety of industries and occupations is of the most importance. It forms the need to develop students' skills of modern technology and equipment application in their professional activity.

The need to integrate these technologies into the processes relating to the preparation of students is also due to the informatization of the economic sphere. Opportunities to maximize the efficiency of the education provided by computer technology, are the visualization of theoretical material, the reducing the effort to verify the knowledge and skills, the attracting of the different types of memory and the resulting increase in the degree of assimilation of teaching materials in the limited time of study, the growth of learning motivation, etc. The use of modern information technology in the learning process allows to raise the efficiency of education to a new level.

To solve the problem of students' economic competence the educational-methodical complex was developed and tested in the study. Its use provides the following stages:

- $\quad$ adaptive - the creation of workplace favorable conditions;

- $\quad$ reproductive-activity - the integration of knowledge through didactic computer environment;

- creative - the perception of the scientific field of "Economics" with the interdisciplinary connections;

- individual-creative - the extraction of the integrative basis of economic competence by the means of operating with information technology to create an overall picture of the world.

In our view, when working with electronic educational complex, a major role is played by professional pedagogical culture of the teacher, educational activity which should include motivational, creative and reflective components.

The main functions of educational-methodical complex are educational, reference and tool.

Educational-methodical complex includes the following types of electronic presentations:

1. Sales presentations. They are used by sales agents in closing transactions, to quickly furnish all the necessary information about the product, its advantages in comparison with the products of firms - competitors.

2. Marketing presentations report basic information about the main activities of the enterprise and products. This type of presentation is intended for advertising goods and economic activities of the company.

3. Corporate presentations introduce new employees and candidates with the tradition of the company and the creative atmosphere in a team, the benefits of working in this structure.

4. Financial presentations represent the financial aspects of the company. Their goal is to obtain funds in the stock market.

5. Special presentations include:

- "Presentation-quidance" that offer the mechanisms by which new products and services are introduced in the market. It addresses to sales representatives;

- $\quad$ "Personal presentation," demonstrate new ideas, recommendations, methods of efficient operation of the invention, developed by a certain employee or a person who takes a particular position in the company;

- $\quad$ "Official presentation of the productive organization of enterprise services activity with the personnel", are presented in the form of interactive information stands.

Designed electronic version of educational-methodical complex corresponds to a number of requirements:

a) the requirements of the educational standard;

b) maximize the use of computer technology capabilities; 
c) the requirements of the open digital resources;

d) has a psychological appeal and meets the ergonomic requirements;

e) contains a video with audio, animation, fitness equipment of standard procedures with the control of the results of their implementation, the computer models of the processes with the change of the initial conditions, the systems of automated monitoring and the evaluation of the level of knowledge;

f) the focus on a particular grade level.

We add that the effect of the use of information technology in the educational process can be evaluated using criteria such as innovation, optimality and effectiveness.

The following criteria and indicators can be used in assessing the formation of the economic competence of students in the education system:

- motivational-valuable (the quality and the traits of a personality, psychological readiness, tolerance);

- reference-cognitive (the assimilation of knowledge, the mastery of the complex of concepts, categories, laws, the level of economic literacy);

- operational-practical (handling operations, which have the economic direction, design skills, organization and implementation of economic activities, the availability of skills, ensuring the rational organization of labor, the application of knowledge in situations of non-standard character).

The formation of motivational-valuable criterion proved the best choice of ways of social and economic problems solving is proved by the use of psychological tests "The Scale of the Assessment of the Needs to Achieve."

The experts concluded that the results on the formation of the reference-cognitive component are positive. These figures are statistically processed by calculating the variance, standard deviation, average values.

Reference-cognitive component is determined by a special test using. The analysis of test results was carried out using evaluation criteria such as scientific character and complete assimilation of concepts, the quality of assimilation, automatism. These criteria are grounded via efficiency factor. In our case its magnitude exceeded one. This suggests that established branches of learning, compared with the traditional, are more effective.

The level of the formation of the operational-practical component is defined by the results of the analysis of the questionnaire "Evaluation of Action on the Economic Situation."

Psychological and pedagogical diagnostics of the results on the determination of the degree of students' economic competence development, was carried out with point-rating control system using. It allowed to identified the growing dynamics of the level of formation of economic competence. This is indicated by the results of progress, both in the reference and experimental groups before and after the experiment.

At the end of the experimental work in groups, some differences in the level of the development of economically important qualities of the person were clearly identified. For example, students in the experimental group showed a higher level of organizational ability, commitment and independence. Here, such indicators as social, flexible thinking, the ability to think strategically are of average and above average level. In the reference group the level of severity of these characteristics is rated as average and below average. Furthermore, it was found that for reference group students the level of the inclination to risk is above average, while in the experimental group this figure was at "below average".

This fact points to the need for teaching students the methods and techniques of rational economic behavior and informed choices making. To this end, in the framework of a special course for experimental group students one should conduct lessons on the formation of the ability to make decisions and to act under time pressure, and the incompleteness of the information.

Thus, experimental studies have confirmed a rather high level of the effectiveness of a special course on "Economic Culture" developed by us for students in the formation of economic competence.

\section{Conclusion}

The authors believe that one of the main problems of modern economic system of vocational education should be the formation of economic literacy of students, the presence of a particular view on the nature of economic relations. These characteristics are manifested in the economic outlook, as well as in the formation of the type of rational human behavior in economic life, and thus in the formation of economic competence.

At the present stage, the connection between quality education and the opportunity to build a civil society, an efficient economy and national security is obvious. In a state oriented on innovative development, it is necessary to let the educational system to move forward, give it initiatives, which is a priority of the project of "Education", "National Security Strategy of the Russian Federation until 2020". 


\section{References}

The Glossary of Terms of the Labor Market (1997). The Development of the Standards of Educational programs and Curricula. European Training Foundation. ETF.

Evseenko, E.I. \& Evseenko F.P. (2002) The Value of Technology as a School Subject in Preparing Students to Work // Students Technological Education: the state, problems and prospects. - Bryansk: Publishing house of BSU.

Raven, J. (2001) A fragment of the book "The Competence in Modern Society" // Psychological Journal. №4. pp. 5-27.

Zimnyaya, I.A. (2004) Key Competence as the Result-targeted Basis of Competence Approach in Education. M.: Omega-L. pp. 38.

Kuz'minov, Ya.I. (1993) Theoretical Economic Culture in Modern Russia // Social studies and the present. №5. pp. 13-23.

Muraveva, M.A., Nazarova O.G. \& Silaeva V.V. (2014) Innovative Directions in the Development of Industrial Marketing // Economy and management in engineering. №2 (32).

Nazarova, O.G. (2008) Economic Competence as a Structural Unit of Economic Culture // Humanization of education. №4.

Uvarova, L.I. (2001) Formation of Economic Culture in the Course of High School Socialization // Modern problems of economic psychology in Russia. Socio-cultural aspect. SPb.: Publishing House of the State University of Economics and Finance.

Formation of Economic Competence of senior pupils // Educational research. URL: http://borytko.nm.ru/papers/subject 5_l/fadeeva.htm (date of access: 18.05.2015).

Hutmacher, Walo (1997) Key Competencies for Europe // Report of the Symposium Bern, Switzezland 27-30 March, 1996. Councie for Cultural Cooperation (CDCC) a// Secondary Education for Europe Strasbourg. 